\title{
Budesonide Foam Has a Favorable Safety Profile for Inducing Remission in Mild-to-Moderate Ulcerative Proctitis or Proctosigmoiditis
}

\author{
David T. Rubin ${ }^{1} \cdot$ William J. Sandborn ${ }^{2} \cdot$ Brian Bosworth $^{3} \cdot$ Salam Zakko $^{4}$ • \\ Glenn L. Gordon ${ }^{5} \cdot$ Mark E. Sale $^{6} \cdot$ Robert L. Rolleri $^{7} \cdot$ Pamela L. Golden $^{7}$ • \\ Andrew C. Barrett ${ }^{7} \cdot$ Enoch Bortey $^{7} \cdot$ William P. Forbes ${ }^{7}$
}

Received: 27 April 2015/Accepted: 3 September 2015/Published online: 19 September 2015

(C) Springer Science+Business Media New York 2015

\begin{abstract}
Background Budesonide foam, a rectally administered, second-generation corticosteroid with extensive hepatic first-pass metabolism, is efficacious for the treatment of mild-to-moderate ulcerative proctitis and ulcerative proctosigmoiditis.

Aim The aim of this study was to comprehensively assess the safety and pharmacokinetic profile of budesonide foam. Methods Data from five phase III studies were pooled to further evaluate safety, including an open-label study
\end{abstract}

Robert L. Rolleri, Pamela L. Golden, Andrew C. Barrett, Enoch Bortey, and William P. Forbes were employees of Salix during this study but are no longer affiliated with the company.

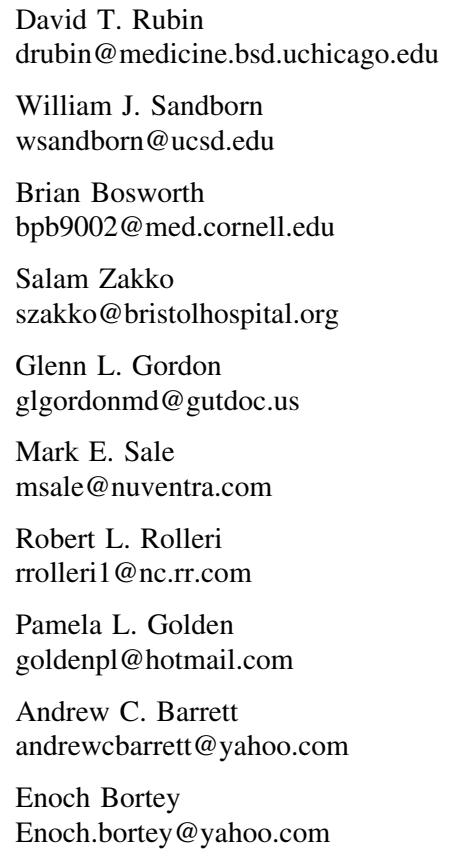

(once-daily treatment for 8 weeks), an active-comparator study (once-daily treatment for 4 weeks), and two placebocontrolled studies and an open-label extension study (twice-daily treatment for 2 weeks, then once daily for 4 weeks). Data from the placebo-controlled studies and two phase I studies (i.e., patients with mild-to-moderate ulcerative colitis and healthy volunteers) were pooled to evaluate the pharmacokinetics of budesonide foam.

Results A similar percentage of patients reported adverse events in the budesonide foam and placebo groups, with the majority of adverse events being mild or moderate in intensity (93.3 vs $96.0 \%$, respectively). Adverse events occurred in 41.4 and $36.3 \%$ of patients receiving budesonide foam and placebo, respectively. Mean morning cortisol concentrations

William P. Forbes

bill.forbes@earthlink.net

1 University of Chicago Medicine, 5841 S. Maryland Avenue, MC 4076, Chicago, IL 60637, USA

2 Division of Gastroenterology, Department of Medicine, University of California San Diego, 9500 Gilman Drive, La Jolla, CA 92093, USA

3 Jill Roberts Center for Inflammatory Bowel Disease, New York-Presbyterian Hospital/Weill Cornell Medical Center, 1315 York Avenue, Mezzanine, New York, NY 10021, USA

4 Connecticut Gastroenterology Institute, Bristol Hospital, 41 Brewster Road, Bristol, CT 06010, USA

5 Center for Digestive and Liver Diseases, Inc., 714 Medical Park Drive, Mexico, MO 65265, USA

6 Nuventra Pharma Sciences, Inc., 2525 Meridian Parkway, Research Triangle Park, NC 27713, USA

7 Salix, a Division of Valeant Pharmaceuticals North America LLC, 400 Somerset Corporate Blvd, Bridgewater, NJ 08807, USA 
remained within the normal range for up to 8 weeks of treatment; there were no clinically relevant effects of budesonide foam on the hypothalamic-pituitary-adrenal axis. Population pharmacokinetic analysis demonstrated low systemic exposure after budesonide foam administration.

Conclusions This integrated analysis demonstrated that budesonide foam for the induction of remission of distal ulcerative colitis is safe overall, with no clinically relevant effects on the hypothalamic-pituitary-adrenal axis.

Keywords Ulcerative colitis - Ulcerative proctitis . Ulcerative proctosigmoiditis - Budesonide foam - Safety . Pharmacokinetics

\section{Introduction}

Ulcerative colitis (UC), a chronic inflammatory bowel disease, is stratified by the extent of colonic involvement: ulcerative proctitis (UP), ulcerative proctosigmoiditis (UPS), left-sided, extensive, and pancolitis [1-3]. In UP, inflammation is limited to the rectum (i.e., distal to the rectosigmoid junction), while inflammation in UPS, considered a form of distal UC, is characterized by rectal and sigmoid inflammation without involvement of the descending colon [2-4]. Approximately $46 \%$ of patients with UC have UP or UPS $[4,5]$. Clinical symptoms of UC include rectal bleeding, diarrhea, urgency, tenesmus, and abdominal pain [1], with some patients with limited distal UC also experiencing paradoxical constipation [6].

First-line therapy for induction of remission is rectal 5-aminosalicylate (5-ASA) formulations (i.e., suppository, foam, or enema) for patients with UP, and rectal 5-ASA alone or in combination with oral 5-ASA for patients with more proximal left-sided disease involvement [7-10]. 5-ASA preparations are slow to act, and for patients with more significant symptoms, rectally administered corticosteroids are considered second-line therapy for induction of more rapid remission in patients with UP or UPS. However, conventional corticosteroids are associated with undesirable systemic effects, which limit their use.

Rectal therapies include suppositories, enemas, or foam preparations. Suppositories are not only difficult for some patients to administer [11], but the use of suppositories is restricted by their limited proximal distribution within the rectum [12], in contrast to foam preparations, which can spread to the descending colon [13]. Foam preparations provide greater retention and more uniform distribution within the distal colon and rectum compared with enema preparations [14-16]. In addition, rectal foam preparations are generally preferred by patients over rectal enema formulations [17].

Budesonide foam, a rectally administered second-generation corticosteroid, has minimal systemic effects due to extensive first-pass metabolism in the liver after absorption. Budesonide foam was efficacious for the treatment of active UP and UPS in four phase III studies, including a randomized, active-controlled, multicenter study [18], and a randomized, double-blind, double-dummy, multicenter study [17]. Also, patients successfully completing two identically designed, placebo-controlled, phase III trials [19] were permitted to continue in a phase III, open-label extension study and receive repeat cycles of budesonide foam for recurrent flares. In this integrated analysis of safety, data from these five phase III studies were pooled for a detailed evaluation of the safety of budesonide foam. In addition, population pharmacokinetics were assessed to characterize the systemic exposure parameters of budesonide foam by pooling data from the two placebocontrolled trials [19] and two phase I trials [13].

\section{Methods}

\section{Safety and Pharmacokinetic Populations}

\section{Safety Population}

The safety population included patients from five studies: two identically designed, placebo-controlled studies conducted in the USA and Russia [BUCF3001 (Clinicaltrials.gov identifier NCT01008410) and BUCF3002 (Clinicaltrials.gov identifier NCT01008423)] [19], an active-comparator (i.e., hydrocortisone foam) study conducted in Germany, Italy, and Israel (BUF-6/UCA) [18], an active-comparator (i.e., budesonide enema) study conducted in Germany, Hungary, Lithuania, Latvia, Estonia, The Netherlands, and Israel (BUF-9/UCA) [17], and an open-label extension study conducted in the USA for patients who completed BUCF3001 and BUCF3002 and had recurrent flares of UP or UPS [BFPS3073 (Clinical Trials.gov identifier NCT01349673)].

In the two phase III, identically designed, multicenter, randomized, double-blind, placebo-controlled studies, patients were randomized 1:1 to receive budesonide foam $2 \mathrm{mg} / 25 \mathrm{~mL}$ or placebo twice daily for 2 weeks, then once daily for 4 weeks [19]. Each study consisted of a screening phase, a run-in/stabilization phase of 4-7 days, a 6-week treatment phase, and a 2-week follow-up phase. Patients $\geq 18$ years of age with active (endoscopy-confirmed) distal UP or UPS, extending $\geq 5 \mathrm{~cm}$, but no further than $40 \mathrm{~cm}$ from the anal verge, and baseline Modified Mayo Disease Activity Index (MMDAI) scores between 5 and 10, inclusive, with subscale ratings $\geq 2$ for endoscopic appearance and rectal bleeding were eligible for enrollment. Concomitant use of oral 5-ASA drugs at a stable dose up to $4.8 \mathrm{~g} /$ day was permitted. Key exclusion criteria included use of systemic, oral, topical, or rectal corticosteroids, or laxatives or enemas (other than 5-ASAs) during the previous 14 days. 
In a phase III, multicenter, randomized, active-comparator (hydrocortisone foam), open-label study, patients were randomized to receive budesonide foam $2 \mathrm{mg} / 20 \mathrm{~mL}$ or hydrocortisone $100 \mathrm{mg} / 15 \mathrm{~mL}$ once daily for 8 weeks [18]. Patients between 18 and 70 years of age with active (endoscopy- and histology-confirmed) UP or UPS and a disease activity index (DAI) $\geq 4$ were eligible for enrollment. Concomitant use of oral 5-ASA drugs at a stable dose up to $2 \mathrm{~g}$ /day was permitted. Key exclusion criteria included use of corticosteroids within 1 month or immunomodulators within 3 months prior to baseline.

In a phase III, multicenter, randomized, double-blind, double-dummy, active-comparator (budesonide enema) study, patients were randomized to receive budesonide foam $2 \mathrm{mg} / 25 \mathrm{~mL}$ and placebo enema or budesonide enema $2 \mathrm{mg} /$ $100 \mathrm{~mL}$ and placebo foam once daily for 4 weeks [17]. Patients between 18 and 70 years of age with active (endoscopy-, histology-, and negative stool culture-confirmed) UP or UPS, a DAI $>4$, and an endoscopic index $\geq 4$ were eligible for enrollment. Concomitant use of 5-ASA drugs and long-term nonsteroidal antiinflammatory drug treatment were not permitted. Key exclusion criteria included use of oral/rectal corticosteroids within 1 month or immunomodulators within 3 months prior to baseline.

In a multicenter, open-label extension study (BFPS3073), patients who completed BUCF3001 and BUCF3002 were permitted to receive additional 6-week treatment cycles of budesonide foam for recurrent flares of UP or UPS. When a flare occurred, budesonide foam $2 \mathrm{mg}$ was administered rectally twice daily for 2 weeks followed by $2 \mathrm{mg}$ oncedaily administration for 4 weeks.

\section{Pharmacokinetics Population}

The pharmacokinetics (PK) population included patients from four studies: two identically designed, placebo-controlled, phase III studies (BUCF3001 and BUCF3002) [19] and two phase I studies [single-dose (BUF-4/BIO) [13], and multiple-dose (BUF-7/BIO)]. In the single-dose, openlabel, single-center, phase I study conducted in Austria, patients with active, mild-to-moderate UC, as defined by the DAI [20], received a dose of ${ }^{99 \mathrm{~m}}$ Tc-labeled budesonide foam $2 \mathrm{mg} / 20 \mathrm{~mL}$ [13]. In the multiple-dose, open-label, single-center, phase I study conducted in Germany, healthy male volunteers received a single dose of budesonide foam $2 \mathrm{mg}$ on day 1 , followed by budesonide foam $2 \mathrm{mg}$ twice daily from days 2 to 5 .

\section{Safety Assessments}

Safety assessments included periodic monitoring of adverse events (AEs), clinical laboratory tests [including morning cortisol concentrations and adrenocorticotropic hormone $(\mathrm{ACTH})$ challenge tests], measurement of vital signs, and monitoring of concomitant medications. For studies that included an ACTH challenge test, patients were administered a $250-\mu \mathrm{g}$ dose of cosyntropin between 8 am and $10 \mathrm{am}$, or approximately within $2-4 \mathrm{~h}$ of waking, via intramuscular injection. Blood for serum cortisol assessments was drawn immediately prior to cosyntropin administration (baseline) and at a 30-min time point after the challenge. Per protocol, adrenal insufficiency was defined as having a serum cortisol concentration of $\leq 18 \mu \mathrm{g} / \mathrm{dL}$ at 30 min following ACTH challenge.

\section{Pharmacokinetic Bioanalysis}

Blood samples for pharmacokinetic assessments were collected, and plasma budesonide concentrations were determined using high-performance liquid chromatography (HPLC)-dual mass spectroscopy. The effect of budesonide foam on the hypothalamic-pituitary-adrenal (HPA) axis was assessed by evaluating correlations of plasma budesonide maximum concentration $\left(C_{\max }\right)$ and area under the curve (AUC) values with results of the week-6 ACTH challenge in studies BUCF3001 and BUCF3002.

\section{Statistical Analyses}

The safety population was defined as any enrolled patient who received $\geq 1$ dose of study medication. Demographic and baseline disease characteristics, exposure, and safety data were summarized using descriptive statistics. Two models were used for the population pharmacokinetic analysis: the traditional forward addition approach and the single-objective hybrid genetic algorithm [SOHGA, DARWIN $^{\mathrm{TM}}$ (Nuventra Pharma Sciences, Research Triangle Park, NC)] [21, 22]. The traditional forward addition approach, which used a $p$ value $<0.05$ for a likelihood ratio test (LRT), was used in combination with diagnostic figures and consideration of biologic plausibility to add features to a trivial model (compartments, mixture models, lag time, covariates). The SOHGA utilizes user-defined criteria to provide a robust method for selecting population PK models, designed to result in a large model $(P<0.05)$, convergence, a successful covariance step, and a successful correlation and condition number test. The two models were combined for a final forward addition/backward elimination process, using the LRT with forward addition and $P<0.05$ and backward elimination with $P<0.01$. The final model used for analysis was a one-compartment model with first-order absorption and an absorption lag time. 


\section{Results}

\section{Patients}

The safety population for budesonide foam included 719 patients from five phase III trials, including two placebocontrolled trials, two active-controlled trials, and one openlabel extension trial (Fig. 1). The safety population for placebo included 278 patients from two phase III placebocontrolled trials. The majority of patients in the placeboand active-controlled studies $(84.3 \%$ of patients in the budesonide foam group and $86.3 \%$ of patients in the placebo group) completed the studies.

Demographic and baseline characteristics were generally similar between groups (Table 1). A greater percentage of patients in the budesonide foam group had mild disease severity compared with the placebo group (26.7 vs $12.2 \%$, respectively). In the overall budesonide foam treatment group, fewer patients used 5-ASAs at baseline compared with the placebo group $(31.7$ vs $55.4 \%$, respectively); this is because concomitant use of 5-ASAs was prohibited in one of the active-controlled studies. However, when only studies that allowed the use of 5-ASAs at baseline were considered in the analysis, a greater percentage of patients receiving budesonide foam versus those receiving placebo also reported using 5-ASAs at baseline (68.9 vs $55.4 \%$, respectively). The mean duration of drug exposure was 46.5 days [standard deviation (SD), 40.1 days] and 39.1 days (SD, 9.2 days) for budesonide foam and placebo groups, respectively. The total number of person-years of exposure was 91.2 in the budesonide foam group and 29.8 in the placebo group.

In the current analysis, AEs were reported by 41.4 and $36.3 \%$ of patients treated with budesonide foam and placebo, respectively (Table 2). Most AEs were mild or moderate in intensity and occurred in a similar percentage of patients in both groups, 93.3 and $96.0 \%$ of patients receiving budesonide foam or placebo, respectively. The most common AEs (reported by $\geq 2 \%$ of patients) in the budesonide foam group were decreased blood cortisol concentrations, headache, abdominal pain, and nausea. Adverse events considered to be at least possibly related to study drug occurred in 15.6 and $5.8 \%$ of patients in the budesonide foam and placebo groups, respectively.

The most common AEs ( $\geq 5$ patients) considered related to treatment with budesonide foam were decreased blood cortisol concentrations $(6.1 \%)$, adrenal insufficiency $(1.8 \%)$, headache $(1.0 \%)$, abdominal pain $(0.8 \%)$, and nausea $(0.7 \%)$. The incidence of glucocorticoid (noncortisol)-related AEs of interest was low and not different between budesonide foam and placebo. Adverse events leading to study discontinuation were observed in 7.9 and $4.3 \%$ of patients in the budesonide foam and placebo groups, respectively. Serious AEs occurred in $8(1.1 \%)$ and $3(1.1 \%)$ patients in the budesonide foam and placebo groups, respectively; no deaths were reported during the studies.

Mean morning cortisol concentrations remained within normal limits in both treatment groups for the duration of treatment, with the majority of patients in each group
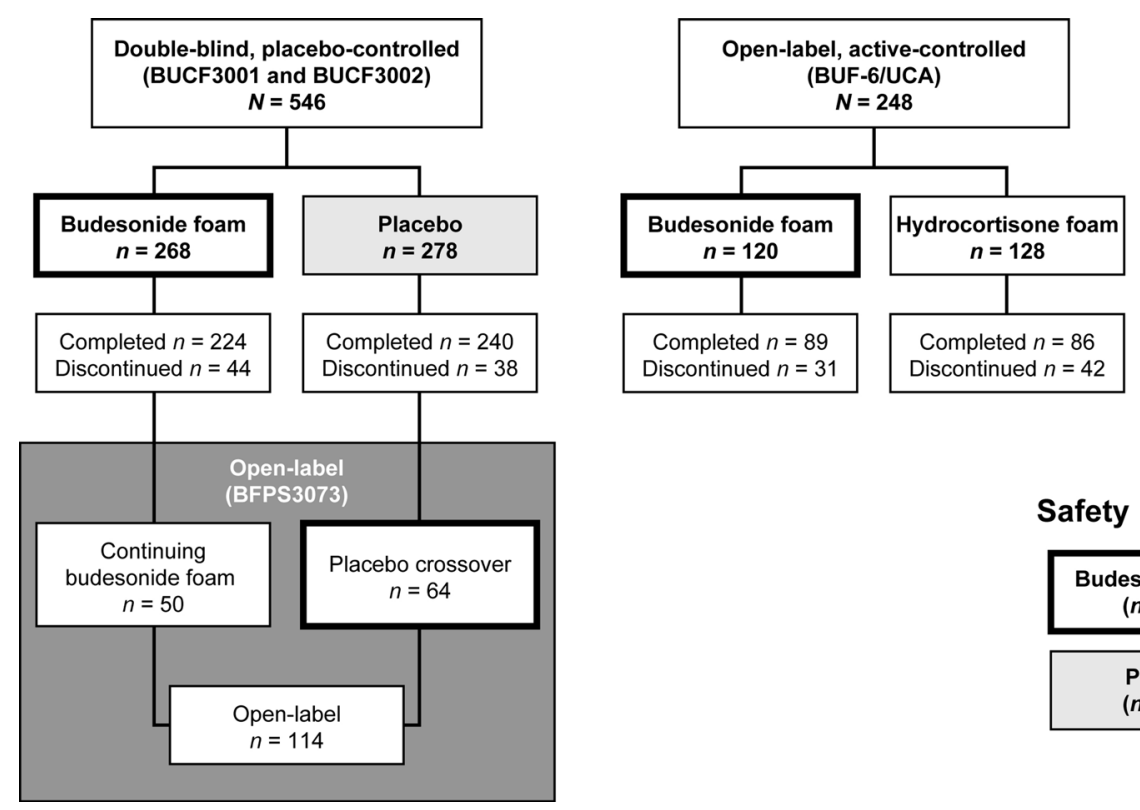

Fig. 1 Patient disposition. The safety population for the budesonide foam group $(n=719)$ included the budesonide foam groups in the two placebo-controlled trials $(n=268)$ and two active-controlled
Safety Population
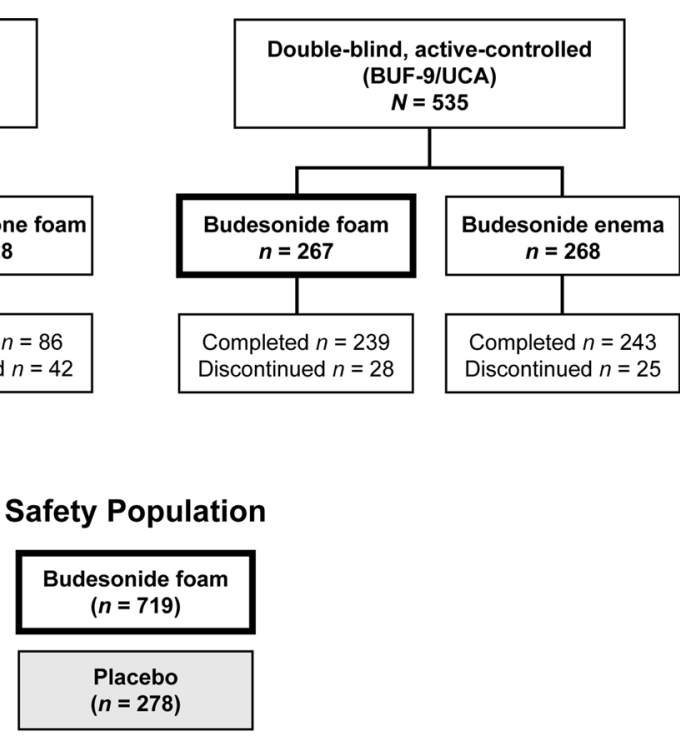

trials $(n=387)$, and the placebo-crossover group $(n=64)$ in the open-label extension study. The safety population for the placebo group $(n=278)$ included patients from two placebo-controlled trials 
Table 1 Demographics and baseline characteristics (safety population)

\begin{tabular}{|c|c|c|}
\hline Characteristic & Budesonide foam $(n=719)$ & Placebo $(n=278)$ \\
\hline Age (year), mean (SD) & $43.4(13.3)$ & $41.6(13.2)$ \\
\hline \multicolumn{3}{|l|}{$\operatorname{Sex}[n(\%)]$} \\
\hline Male & $342(47.6)$ & $115(41.4)$ \\
\hline Female & $377(52.4)$ & $163(58.6)$ \\
\hline \multicolumn{3}{|l|}{ Race $[n(\%)]$} \\
\hline White & $672(93.5)$ & $257(92.4)$ \\
\hline Black & $33(4.6)$ & $13(4.7)$ \\
\hline Other & $14(1.9)$ & $8(2.9)$ \\
\hline Body mass index $\left(\mathrm{kg} / \mathrm{m}^{2}\right)$, mean (SD) & $25.7(4.9)^{\mathrm{a}}$ & $26.0(5.1)$ \\
\hline Duration of disease (year), mean (SD) & $5.9(7.3)$ & $4.4(6.0)$ \\
\hline \multicolumn{3}{|l|}{ Extent of disease $[n(\%)]$} \\
\hline Proctitis $^{b}$ & $241(33.5)$ & $81(29.1)$ \\
\hline Proctosigmoiditis ${ }^{\mathrm{c}}$ & $475(66.1)$ & $196(70.5)$ \\
\hline Missing & $3(0.4)$ & $1(0.4)$ \\
\hline \multicolumn{3}{|l|}{ Severity of disease $[n(\%)]^{\mathrm{d}}$} \\
\hline MMDAI score $<4$ & $4(0.6)$ & 0 \\
\hline Mild & $192(26.7)$ & $34(12.2)$ \\
\hline Moderate & $505(70.2)$ & $244(87.8)$ \\
\hline Severe & $14(1.9)$ & 0 \\
\hline Missing & $4(0.6)$ & 0 \\
\hline Baseline use of 5-ASA $[n(\%)]$ & $228(31.7)$ & $154(55.4)$ \\
\hline
\end{tabular}

5-ASA 5-aminosalicylic acid, CAI clinical disease activity index, DAI disease activity index, MMDAI Modified Mayo Disease Activity Index

${ }^{\text {a }} n=715$

b Proctitis was defined as disease limited to the rectum (up to $\sim 15 \mathrm{~cm}$ from the anal verge)

c Proctosigmoiditis was defined as disease limited to the rectum and sigmoid colon (up to $\sim 40 \mathrm{~cm}$ from the anal verge)

d Mild (MMDAI score 4-6); moderate (MMDAI score 7-10), and severe (MMDAI score 11-12) in BUCF3001 and BUCF3002. Assessment of disease severity in study BUF-6/UCA by DAI and in study BUF-9/UCA by CAI and DAI $[17,18]$ maintaining total cortisol concentrations above the lower limit of normal (>138 nmol/L; 83.0 vs $93.1 \%$ for budesonide foam and placebo groups, respectively; Fig. 2). Although there was a slight decrease in mean morning cortisol concentrations at weeks 1 and 2 during twice-daily dosing in the budesonide foam group, the concentrations were similar to baseline values by week 4 . Further, the majority of patients receiving budesonide foam or placebo also maintained normal responses to ACTH challenge at week 6 (86.1 vs $96.2 \%$, respectively; Table 3).

\section{Pharmacokinetics}

Overall, 1296 observations were available from a total of 145 patients and healthy volunteers in the PK population: 12 patients with mild-to-moderate UC from a phase I, single-dose study, 18 healthy volunteers from a phase I multiple-dose study, and 115 patients with mild-to-moderate UP or UPS from two placebo-controlled phase III trials. Overall, the PK population was $58.6 \%$ male and $87.6 \%$ white, with a mean age of 42.3 years.

Plasma concentrations of budesonide were below the limit of quantitation $(0.03 \mathrm{ng} / \mathrm{mL})$ in $33 \%$ of samples from patients in the two placebo-controlled phase III trials. Mean plasma budesonide concentrations in samples from patients with concentrations above the limit of quantitation were similar to those of samples from healthy volunteers in the phase I multiple-dose study.

The estimated mean $C_{\max }$ and mean AUC in the overall PK population were $0.57 \mathrm{ng} / \mathrm{mL}$ and $4.31 \mathrm{ng} \mathrm{h} / \mathrm{mL}$, respectively (Table 4 ). There were no substantial differences between patients with UC and healthy volunteers for the PK parameters estimated. However, in the 115 patients with UC, there was a statistically significant effect of UC symptom severity on the elimination rate constant.

ACTH challenge test results at week 6 were compared with estimates of plasma budesonide $C_{\max }$ and AUC values in combined data from BUCF3001 and BUCF3002. In this 
Table 2 Summary of adverse events (safety population)

\begin{tabular}{lll}
\hline Adverse event $[n(\%)]$ & Budesonide foam $(n=719)$ & Placebo $(n=278)$ \\
\hline Any AE & $298(41.4)$ & $101(36.3)$ \\
Drug-related AE & $112(15.6)$ & $16(5.8)$ \\
AE leading to discontinuation & $57(7.9)$ & $12(4.3)$ \\
Serious AE & $8(1.1)$ & $3(1.1)$ \\
Most common AEs ${ }^{\mathrm{b}}$ & & $6(2.2)$ \\
Decreased blood cortisol concentration & $66(9.2)$ & $7(2.5)$ \\
Headache & $45(6.3)$ & $4(1.4)$ \\
Abdominal pain & $26(3.6)$ & $2(0.7)$ \\
Nausea & $18(2.5)$ & $6(2.2)$ \\
Ulcerative proctitis & 0 & 0 \\
Glucocorticoid-related AEs & & 0 \\
Acne & $4(0.6)$ & $1(0.4)$ \\
Agitation & $1(0.1)$ & $1(0.4)$ \\
Depression & $4(0.6)$ & 0 \\
Insomnia & $3(0.4)$ & $1(0.4)$ \\
Sleep disorder & $1(0.1)$ & $2(0.3)$ \\
Weight increase & C &
\end{tabular}

$A E$ adverse event, $S A E$ serious adverse event, $U C$ ulcerative colitis

${ }^{a}$ SAEs reported in budesonide foam group were: UC in two patients (severe in one patient and moderate in one patient), severe abdominal pain, severe acute exanthematous pustulosis (only drug-related SAE observed), severe arterial thrombosis limb, moderate diarrhea, moderate hypersensitivity, and mild unstable angina in one patient each; in the placebo group: severe anemia, ectopic pregnancy of moderate severity, and moderate UC in one patient each

b $\geq 2 \%$ of patients in any group
Fig. 2 Mean morning cortisol concentrations up to 8 weeks for budesonide foam group and 6 weeks for placebo group. Data are from the randomizedcontrolled trials (placebo- and active-controlled trials). Error bars indicate standard deviations. Morning cortisol concentration results recorded as a threshold value rather than exact value were not imputed as data for the figure

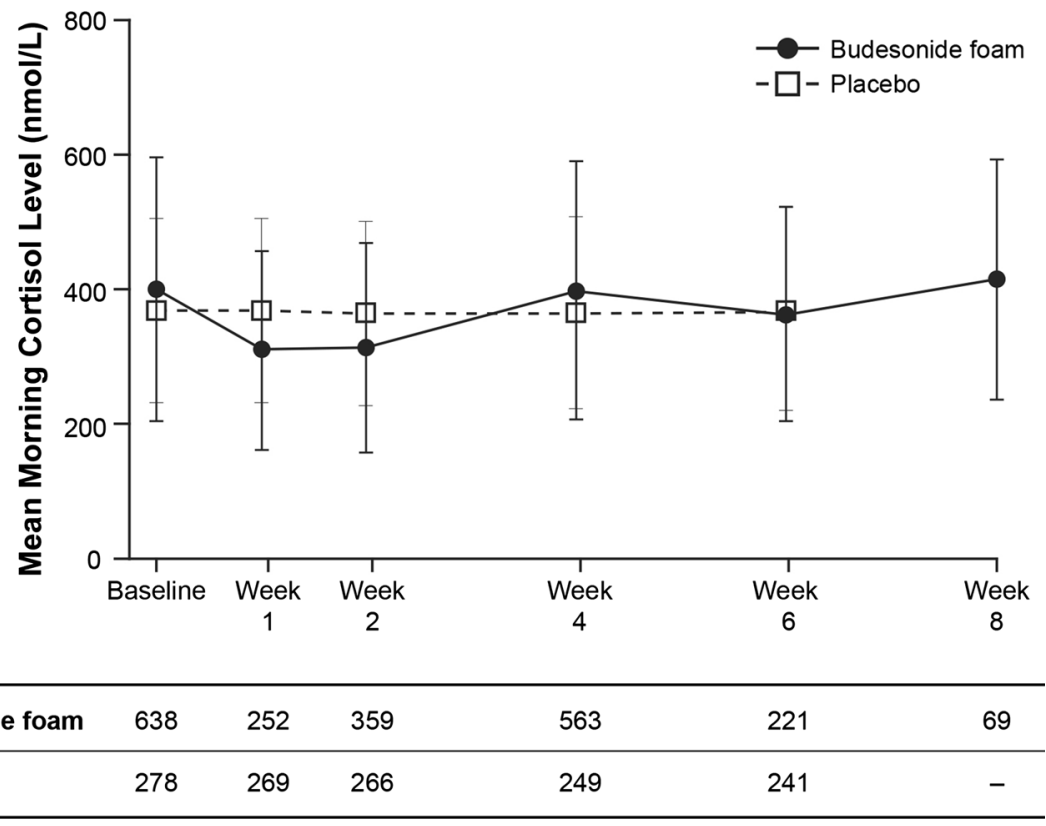

comparison, a negative correlation between ACTH challenge sensitivity, measured as the increase in serum cortisol level in response to ACTH challenge, and plasma budesonide $C_{\max }$ or AUC would be evidence of a biologically plausible association between budesonide plasma concentrations and adrenal suppression. However, no negative correlation between sensitivity to ACTH challenge and budesonide plasma $C_{\max }$ or AUC values was observed. 
Table 3 Total cortisol concentrations and normal response to ACTH challenge (randomized safety population)

\begin{tabular}{|c|c|c|}
\hline Parameter, $n / N^{\mathrm{a}}(\%)$ & Budesonide foam $(n=655)^{\mathrm{b}}$ & Placebo $(n=278)^{\mathrm{b}}$ \\
\hline \multicolumn{3}{|c|}{ Total cortisol $>5 \mu \mathrm{g} / \mathrm{dL}(138 \mathrm{nmol} / \mathrm{L})^{\mathrm{c}}$} \\
\hline Baseline & $622 / 638(97.5)$ & 275/278 (98.9) \\
\hline Week 1 & $224 / 263(85.2)$ & $264 / 269(98.1)$ \\
\hline Week 2 & $315 / 366(86.1)$ & $263 / 266(98.9)$ \\
\hline Week 4 & $539 / 565(95.4)$ & $243 / 249(97.6)$ \\
\hline Week 6 & $211 / 224(94.2)$ & $234 / 241(97.1)$ \\
\hline Week 8 & $65 / 69(94.2)$ & - \\
\hline \multicolumn{3}{|c|}{ Normal response to ACTH challenge $\mathrm{e}^{\mathrm{d}, \mathrm{e}}$} \\
\hline Baseline & $261 / 266(98.1)$ & 275/278 (98.9) \\
\hline Week 6 & $186 / 216(86.1)$ & $226 / 235(96.2)$ \\
\hline \multicolumn{3}{|c|}{$A C T H$ adrenocorticotropic hormone } \\
\hline \multicolumn{3}{|c|}{ a Denominator $N$ is the number of patients with a value at each given week during the study } \\
\hline \multicolumn{3}{|c|}{ b Only patients in the four randomized studies were included } \\
\hline \multicolumn{3}{|c|}{${ }^{\mathrm{c}}$ Lower limit of normal } \\
\hline \multicolumn{3}{|c|}{$\begin{array}{l}\text { d The normal response to ACTH challenge, defined by protocol as a cortisol concentration of }>18 \mu \mathrm{g} / \mathrm{dL} \\
(500 \mathrm{nmol} / \mathrm{L}) \text { at } 30 \mathrm{~min} \text { following ACTH challenge }\end{array}$} \\
\hline
\end{tabular}

Table 4 Noncompartmental parameter estimates

\begin{tabular}{ll}
\hline Parameter, mean $(\mathrm{CV})$ & $\begin{array}{l}\text { Pharmacokinetic population } \\
(N=145)\end{array}$ \\
\hline Clearance/F (L/h) & $464(640)$ \\
Volume of distribution/F (L) & $2700(274)$ \\
Absorption lag time (h) & 0.149 \\
AUC (ng h/mL) & $4.31(64)$ \\
$C_{\max }(\mathrm{ng} / \mathrm{mL})$ & $0.573(37)$ \\
\hline
\end{tabular}

$A U C$ area under the curve, $C_{\max }$ maximum plasma concentration, $C V$ coefficient of variation, $F$ absolute bioavailability

\section{Discussion}

In this integrated analysis of safety from five phase III trials, budesonide foam administered rectally for up to 8 weeks was shown, overall, to be safe for patients with mild-tomoderate UP or UPS, as treatment with budesonide foam was associated with a low incidence of AEs. Pooling of safety data for $>700$ patients exposed to budesonide foam provided a robust assessment of the overall safety and allowed for a better review of potentially uncommon AEs in a larger patient population than was possible to assess from each individual study alone. These data represent a comprehensive report regarding the safety of budesonide foam for the treatment of patients with UP or UPS. Budesonide foam has previously been shown to be efficacious for the induction of remission in this patient population [17, 18, 23].

The incidence and severity of AEs and severe AEs reported in this analysis were generally similar between budesonide foam and placebo groups [18]. No clinically significant adrenal suppression with budesonide foam therapy was detected, confirming results from previous studies with rectal budesonide preparations that showed serum cortisol concentrations within normal range [24, 25]. These data are consistent with results observed with shortterm administration of oral budesonide preparations [2630]. This is likely because budesonide undergoes extensive ( $90 \%$ ) hepatic first-pass metabolism, forming metabolites with little or no activity [31-33]. The incidence of glucocorticoid (noncortisol)-related AEs, such as sleep changes, acne, and weight gain, were rare and were similar between budesonide foam and placebo groups; however, assessment of potential glucocorticoid effects was not prespecified in all study protocols. Serum cortisol concentrations had the greatest decrease during weeks 1 and 2, compared with weeks 4 and 6; this effect was likely driven by twice-daily dosing in weeks 1 and 2 in studies BUCF3001 and BUCF3002, followed by subsequent daily dosing for the last 4 weeks of these studies.

The population-based PK analysis demonstrated low systemic exposure of budesonide foam. Budesonide foam has a local-to-systemic exposure ratio of $>40,000$ to 1 , consistent with its local site of action in the distal colon. Increases in budesonide systemic exposure $\left(C_{\max }\right.$ and AUC) did not correlate with diminished response to ACTH challenge. The majority of patients treated with budesonide foam or placebo had normal HPA function with the ACTH challenge test at week 6 , findings driven by the BUCF3001 and BUCF3002 studies. These results suggest that exposure to rectally administered budesonide at the doses studied for up to 6-8 weeks does not have clinically relevant effects on the HPA axis. 
A potential study limitation is that this analysis included data from studies with minor differences in disease severity, inclusion and exclusion criteria, and study duration. Also, whether concomitant use of 5-ASAs at baseline was permitted differed between the studies included in this analysis. In the overall study population, a greater percentage of patients receiving placebo used 5-ASAs at baseline; however, two studies did not permit concomitant use of 5-ASAs at baseline. When these two studies were excluded from analysis, the majority of patients receiving budesonide foam used 5-ASAs at baseline. It is unclear whether baseline use of 5-ASAs influenced the safety profile of budesonide foam. However, a subgroup analysis (BUCF3001 and BUCF3002 studies) evaluating the potential impact of oral 5-ASA use on the efficacy and safety of budesonide foam supports that baseline oral 5-ASA use does not impact the tolerability and safety profile of budesonide foam [34].

Results of this integrated analysis demonstrated a short absorption lag time and a rapid absorption rate. A positive finding from this analysis was the lack of a relationship between presence of UP and UPS and PK parameters; however, the severity of disease symptoms was predictive of the elimination rate constant, with more severe symptoms predictive of decreased elimination. Comparisons of PK parameters between rectally administered budesonide foam and oral formulations of budesonide are limited by the lack of pharmacokinetic data from oral formulations available in patients with UP or UPS [35].

The findings of this comprehensive safety analysis, together with published efficacy results, offer healthcare providers and patients an additional rectally administered therapeutic option for the induction of remission of UP and UPS. Budesonide foam has a low incidence of clinically relevant effects on the HPA axis as shown using ACTH challenge and has a favorable safety profile, most likely related to its minimal systemic exposure. While 5-ASA treatment remains first-line therapy for the induction of remission in patients with mild-to-moderate UP or UPS [2, $7,9,10]$, budesonide foam may be an efficacious and better-tolerated alternative to systemic corticosteroids for the treatment of mild-to-moderate UP or UPS. Indeed, orally administered budesonide MMX has been shown to have a favorable safety profile, with demonstrated efficacy for the induction of remission of mild-to-moderate UC [27, 28]. Availability of both oral and rectal formulations makes it possible for budesonide therapy to be integrated in the current treatment algorithm: as an option after 5-ASAs and before treatment with systemic corticosteroids [36]. In conclusion, rectally administered budesonide foam had a low incidence of AEs in this integrated safety analysis and did not appear to adversely affect the HPA axis when used to treat patients with mild-to-moderate distal UC.
Acknowledgments Technical editorial assistance was provided, under the direction of the authors, by Sophie Bolick, $\mathrm{PhD}$, Synchrony Medical Communications, LLC, West Chester, PA. Funding for this support was provided by Salix, a Division of Valeant Pharmaceuticals North America LLC, Bridgewater, NJ, USA.

\section{Compliance with ethical standards}

Conflict of interest David Rubin has received grant/research support and/or has served as a consultant for AbbVie, Emmi Solutions, Genentech, Janssen Pharmaceuticals, Inc., Prometheus Laboratories, Inc., Santarus, Inc. (previously a wholly owned subsidiary of Salix, a Division of Valeant Pharmaceuticals North America LLC), Shire, Takeda Pharmaceutical Co., Ltd., Telsar Pharma, Inc., UCB Pharma, and Warner Chilcott; and is a co-founder of the nonprofit medication education entity Cornerstones Health, Inc. William Sandborn has served as a consultant for AbbVie, ActoGeniX NV, AGI Therapeutics, plc, Alba Therapeutics Corp., Albireo, Alfa Wassermann, AMPharma BV, Amgen, Anaphore, Aptalis, Astellas, Athersys, Inc., Atlantic Healthcare plc., BioBalance Corp., Boehringer-Ingelheim, Bristol-Myers Squibb, Celek Pharmaceuticals, Celgene, Cellerix SA, Cerimon Pharmaceuticals, ChemoCentryx, CoMentis, Coronado Biosciences, Cosmo Technologies Ltd., Cytokine Pharmasciences, Eagle Pharmaceuticals, Eisai Medical Research Inc., Elan Pharmaceuticals, Eli Lilly, EnGene, Inc., Enteromedics, Exagen Diagnostics, Inc., Ferring Pharmaceuticals, Flexion Therapeutics, Inc., Funxional Therapeutics Limited, Genentech, Genzyme Corp., Gilead Sciences, Given Imaging, GlaxoSmithKline, Human Genome Sciences, Ironwood Pharmaceuticals, Janssen, KaloBios Pharmaceuticals, Inc., Lexicon Pharmaceuticals, Lycera Corporation, Meda Pharmaceuticals, Merck \& Co., Merck Research Laboratories, MerckSerono, Millennium Pharmaceuticals, Nisshin Kyorin Pharmaceutical Co., Ltd., Novo Nordisk A/S, NPS Pharmaceuticals, Optimer Pharmaceuticals, Orexigen Therapeutics, Inc., PDL BioPharma, Pfizer, Procter and Gamble, Prometheus Laboratories, ProtAb Ltd., Purgenesis Technologies, Inc., Receptos, Relypsa, Inc., S.L.A. Pharma (UK) Ltd., Salient Pharmaceuticals, Salix, Santarus, Inc., Shire, Sigmoid Pharma Ltd., Sirtris Pharmaceuticals, Inc., Targacept, Teva Pharmaceutical Industries, Ltd., Therakos, Tillotts Pharma AG, TxCell SA, UCB, Vascular Biogenics Ltd., Viamet Pharmaceuticals, and Warner Chilcott UK Ltd.; he has received speakers' bureau fees for AbbVie, Bristol-Myers Squibb, and Janssen; and he has received financial support for research from AbbVie, Bristol-Myers Squibb, Genentech, GlaxoSmithKline, Janssen, Millennium Pharmaceuticals, Novartis, Pfizer, Procter and Gamble, Shire, and UCB. Brian Bosworth is a consultant, is on the speakers' bureau for, and has received research grants from Salix. Salam Zakko serves as principal investigator on a variety of research protocols for, receives unrestricted grants from, and serves on the speakers' bureau for Salix. Glenn Gordon is a consultant, is on the speakers' bureau, and has received research grants from Salix; serves as a consultant to and is on the speakers' bureau for AbbVie, Aptalis, Janssen, Prometheus Laboratories, sanofi-aventis US LLC, Takeda Pharmaceutical Co., Ltd., UCB, and Warner Chilcott UK Ltd.; has received research grants from AbbVie, Aptalis, Avaxia Biologics, Inc., Coronado Biosciences, Cubist Pharmaceuticals, Dr. Falk Pharma GmbH, Evoke Pharma, Ferring Pharmaceuticals, Furiex Pharmaceuticals, GlaxoSmithKline, Hutchinson MediPharma Ltd., Janssen, Lexicon Pharmaceuticals, Pfizer Inc., Prometheus Laboratories, Red Hill BioPharma Ltd., Revogenex Inc., sanofi-aventis U.S. LLC, Shire, Takeda Pharmaceutical Co., Ltd., Theravance, Tranzyme, United Biosource Corporation, UCB, Ventrus Biosciences, and Warner Chilcott UK Ltd. Mark Sale is a consultant for Salix. Robert Rolleri, Pamela Golden, Andrew Barrett, Enoch Bortey, and William Forbes are former employees of Salix. 


\section{References}

1. Ordás I, Eckmann L, Talamini M, Baumgart DC, Sandborn WJ. Ulcerative colitis. Lancet. 2012;380:1606-1619.

2. Dignass A, Eliakim R, Magro F, et al. Second European evidence-based consensus on the diagnosis and management of ulcerative colitis part 1: definitions and diagnosis. J Crohns Colitis. 2012;6:965-990.

3. Silverberg MS, Satsangi J, Ahmad T, et al. Toward an integrated clinical, molecular and serological classification of inflammatory bowel disease: Report of a Working Party of the 2005 Montreal World Congress of Gastroenterology. Can J Gastroenterol. 2005;19 Suppl A:5A-36A.

4. Hanauer SB, Present DH, Rubin DT. Emerging issues in ulcerative colitis and ulcerative proctitis: individualizing treatment to maximize outcomes. Gastroenterol Hepatol (N Y). 2009;5:4-16.

5. Farmer RG, Easley KA, Rankin GB. Clinical patterns, natural history, and progression of ulcerative colitis. a long-term followup of 1116 patients. Dig Dis Sci. 1993;38:1137-1146.

6. Regueiro MD. Diagnosis and treatment of ulcerative proctitis. $J$ Clin Gastroenterol. 2004;38:733-740.

7. Kornbluth A, Sachar DB. The Practice Parameters Committee of the American College of Gastroenterology. Ulcerative colitis practice guidelines in adults: American College of Gastroenterology, Practice Parameters Committee. Am J Gastroenterol. 2010;105:501-523.

8. Dignass A, Lindsay JO, Sturm A, et al. Second European evidence-based consensus on the diagnosis and management of ulcerative colitis part 2: current management. J Crohns Colitis. 2012;6:991-1030.

9. Marshall JK, Thabane M, Steinhart AH, Newman JR, Anand A, Irvine EJ. Rectal 5-aminosalicylic acid for induction of remission in ulcerative colitis. Cochrane Database Syst Rev. 2010;1: CD004115.

10. Regueiro M, Loftus EV Jr, Steinhart AH. Cohen RD; Inflammatory Bowel Disease Center. Clinical guidelines for the medical management of left-sided ulcerative colitis and ulcerative proctitis: summary statement. Inflamm Bowel Dis. 2006;12:972-978.

11. Marteau P, Crand J, Foucault M, Rambaud JC. Use of mesalazine slow release suppositories $1 \mathrm{~g}$ three times per week to maintain remission of ulcerative proctitis: a randomised double blind placebo controlled multicentre study. Gut. 1998;42:195-199.

12. Loew BJ, Siegel CA. Foam preparations for the treatment of ulcerative colitis. Curr Drug Deliv. 2012;9:338-344.

13. Brunner M, Vogelsang H, Greinwald R, et al. Colonic spread and serum pharmacokinetics of budesonide foam in patients with mildly to moderately active ulcerative colitis. Aliment Pharmacol Ther. 2005;22:463-470.

14. Cortot A, Maetz D, Degoutte E, et al. Mesalamine foam enema versus mesalamine liquid enema in active left-sided ulcerative colitis. Am J Gastroenterol. 2008;103:3106-3114.

15. Ruddell WS, Dickinson RJ, Dixon MF, Axon AT. Treatment of distal ulcerative colitis (proctosigmoiditis) in relapse: comparison of hydrocortisone enemas and rectal hydrocortisone foam. Gut. 1980;21:885-889.

16. Campieri M, Corbelli C, Gionchetti P, et al. Spread and distribution of 5-ASA colonic foam and 5-ASA enema in patients with ulcerative colitis. Dig Dis Sci. 1992;37:1890-1897.

17. Gross V, Bar-Meir S, Lavy A, The International Budesonide Foam Study Group, et al. Budesonide foam versus budesonide enema in active ulcerative proctitis and proctosigmoiditis. Aliment Pharmacol Ther. 2006;23:303-312.
18. Bar-Meir S, Fidder HH, Faszczyk M, The International Budesonide Study Group, et al. Budesonide foam vs. hydrocortisone acetate foam in the treatment of active ulcerative proctosigmoiditis. Dis Colon Rectum. 2003;46:929-936.

19. Sandborn WJ, Bosworth B, Zakko S, et al. Budesonide foam induces remission in patients with mild-moderate ulcerative proctitis and ulcerative proctosigmoiditis. Gastroenterology. 2015;148:740-750.

20. Sutherland LR, Martin F, Greer S, et al. 5-aminosalicylic acid enema in the treatment of distal ulcerative colitis, proctosigmoiditis, and proctitis. Gastroenterology. 1987;92:1894-1898.

21. Sale M, Sherer EA. A genetic algorithm based global search strategy for population pharmacokinetic/pharmacodynamic model selection. Br J Clin Pharmacol. 2015;79:28-39.

22. Sherer EA, Sale ME, Pollock BG, et al. Application of a singleobjective, hybrid genetic algorithm approach to pharmacokinetic model building. J Pharmacokinet Pharmacodyn. 2012;39:393414.

23. Hammond A, Andus T, Gierend M, et al. Controlled, open, randomized multicenter trial comparing the effects of treatment on quality of life, safety and efficacy of budesonide foam and betamethasone enemas in patients with active distal ulcerative colitis. Hepato-gastroenterology. 2004;51:1345-1349.

24. Hanauer SB, Robinson M, Pruitt R, et al. Budesonide enema for the treatment of active, distal ulcerative colitis and proctitis: a dose-ranging study. U.S. Budesonide enema study group. Gastroenterology. 1998;115:525-532.

25. Lofberg R, Ostergaard TO, Langholz E, et al. Budesonide versus prednisolone retention enemas in active distal ulcerative colitis. Aliment Pharmacol Ther. 1994;8:623-629.

26. Prantera C, Marconi S. Glucocorticosteroids in the treatment of inflammatory bowel disease and approaches to minimizing systemic activity. Therap Adv Gastroenterol. 2013;6:137-156.

27. Sandborn WJ, Travis S, Moro L, et al. Once-daily budesonide $\operatorname{MMX}(\mathrm{R})$ extended-release tablets induce remission in patients with mild to moderate ulcerative colitis: results from the CORE I study. Gastroenterology. 2012;143:1218-1226.

28. Travis SP, Danese S, Kupcinskas L, et al. Once-daily budesonide MMX in active, mild-to-moderate ulcerative colitis: results from the randomised CORE II study. Gut. 2014;63:433-441.

29. Tremaine WJ, Hanauer SB, Katz S, et al. Budesonide CIR capsules (once or twice daily divided-dose) in active Crohn's disease: a randomized placebo-controlled study in the United States. Am J Gastroenterol. 2002;97:1748-1754.

30. Thomsen OO, Cortot A, Jewell D, et al. A comparison of budesonide and mesalamine for active Crohn's disease. International Budesonide-Mesalamine Study Group. $N$ Engl J Med. 1998;339:370-374.

31. Ryrfeldt $\AA$, Andersson P, Edsbäcker S, Tönnesson M, Davies D, Pauwels R. Pharmacokinetics and metabolism of budesonide, a selective glucocorticoid. Eur J Respir Dis Suppl. 1982;122: $86-95$.

32. Andersson P, Edsbacker S, Ryrfeldt A, Von BC. In vitro biotransformation of glucocorticoids in liver and skin homogenate fraction from man, rat and hairless mouse. J Steroid Biochem. 1982;16:787-795.

33. Dahlberg E, Thalen A, Brattsand R, et al. Correlation between chemical structure, receptor binding, and biological activity of some novel, highly active, 16 alpha, 17 alpha-acetal-substituted glucocorticoids. Mol Pharmacol. 1984;25:70-78.

34. Sandborn WJ, Bosworth B, Rubin DT, et al. Efficacy and tolerability of budesonide foam with or without baseline 5-aminosalicylic acid use in patients with ulcerative proctitis or ulcerative 
proctosigmoiditis: results of 2 randomized, placebo-controlled, phase 3 studies. Presented at: American College of Gastroenterology (ACG) Annual Scientific Meeting; October 17-22, 2014; Philadelphia, PA. Poster P470.

35. Brunner M, Ziegler S, Di Stefano AF, et al. Gastrointestinal transit, release and plasma pharmacokinetics of a new oral budesonide formulation. Br J Clin Pharmacol. 2006;61:31-38.
36. Danese S, Siegel CA, Peyrin-Biroulet L. Review article: integrating budesonide-MMX into treatment algorithms for mild-tomoderate ulcerative colitis. Aliment Pharmacol Ther. 2014;39:1095-1103. 